Click www.researchjournal.co.in/online/subdetail.html to purchase.

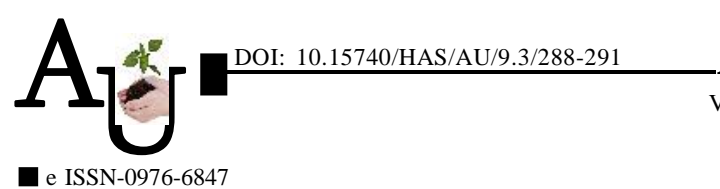

\title{
Research Article Yield and impact analysis of training and FLDs regarding scientific cultivation of brinjal
}

\author{
B.M. TANDEL, K.A. SHAH, PRABHU NAYAKA AND Y. N. TANDEL
}

Article Chronicle:

Received :

20.02.2014;

Revised :

19.05.2014;

Accepted :

05.06.2014

\section{KeY Words :}

Technology index, FLD, Demonstration, Knowledge, Adoption
SUMMARY : Front line demonstration (FLD) is one of the most powerful tools for transfer of technology. In order to increase the productivity of brinjal (Solanum melongena L.) by adopting improved technologies, several demonstrations with scientific package of practices were conducted by Krishi Vigyan Kendra, Navsari. A study on impact of farmer's knowledge, adoption and knowledge regarding scientific innovations was conducted. The impact assessment was based on the comparison of before contact and after contact of KVK with reference to increase in knowledge level of farmer's regarding scientific packages of practices, extent of adoption of INM technology. It was found that the overall knowledge of INM demonstrations indicated that low, medium and high level of knowledge before contact with the KVK was 49 per cent, 38 per cent and 13 per cent, respectively. It was altered up to 08 per cent, 50 per cent and 42 per cent, respectively after contact with the KVK. In case of knowledge regarding selected scientific innovations for demonstrations, high knowledge regarding selected scientific innovations was found. The technology index indicates the feasibility of evolved technology at the farmer's field. Lower the value of technology index, more is the feasibility of technology demonstrated. As such reduction of technology index from 29.05 per cent (2009) to 32.82 per cent (2011) exhibited the feasibility of technology demonstrated.

How to cite this article : Tandel, B.M., Shah, K.A., Prabhu, Nayaka and Tandel, Y.N. (2014). Yield and impact analysis of training and FLDs regarding scientific cultivation of brinjal. Agric. Update, 9(3): 288-291.
Author for correspondence :

\section{B.M. TANDEL}

Krishi Vigyan Kendra,

NAVSARI (GUJARAT)

INDIA

Email: hariombhupi@gmail. com, hariombhupi@nau.in

See end of the article for authors' affiliations 